\title{
DEVELOPMENT POTENTIALS AND STRATEGIC OBJECTIVES OF INTELLIGENT TRANSPORT SYSTEMS IMPROVING ROAD SAFETY
}

\author{
Gábor Pauer \\ Centre for Road Safety \\ KTI Institute for Transport Sciences Nonprofit Ltd \\ H-1119, Budapest Than Károly u. 3-5 \\ e-mail:pauer.gabor@kti.hu
}

\begin{abstract}
Reducing the number of road accident victims is a declared purpose of the European Union. Intelligent Transport Systems (ITS) are able to contribute to this by warning and supporting the drivers, therefore improving road safety. The aim of our research was to analyze the safety aspects of ITS systems, structuring the solutions, analyzing and exploring the opportunities for development. Strategic objectives have been evaluated and relevant processes for achieving them have been summarized. The research efficiently contributes to the utilization of development potentials of ITS systems.
\end{abstract}

Keywords: Intelligent Transport System, road safety, strategy

\section{Introduction}

Over the past decade, road traffic accident rates were characterized by steady improvement. This trend came to a halt in the previous two years. The obligation to fulfil the objectives of the European Union and to reduce the financial losses associated with traffic accidents is a priority for national economies (Elvik, 2000), (Garcia-Altés and Pérez, 2007), (Torok, 2015), (Yang et al., 2013). Innovative solutions based on infocommunication technologies (ICT) and new intelligent systems improving road safety play a significant role in this, so application of them is strategically important.

Intelligent Transport Systems (ITS) improve the efficiency of transport systems by integrating information technologies. These solutions harmonize transport processes, improve the exploitation of capacities, predictability, controllability, security and communication methods. Their beneficent effects on road safety have been investigated in several publications like (Hughes et al., 2015), (Jarasuniene and Jakubauskas, 2007), (Khorasani et al., 2013), (Oei and Polak, 2002) and (Rosolino et al., 2014).

Exploring development opportunities and specifying strategic objectives contribute to better utilization of potentials of these systems in the future (Torok, 2016a). In this paper, ITS solutions with impact on road safety have been collected and classified into groups. The development opportunities of the groups have been revealed; strategic objectives have been evolved and evaluated according to complex criteria, with analytical methods. Finally, relevant steps and processes for achieving the objectives have been summarized.

\section{The Analysis, Classification and Evaluation of Current Intelligent Transport Systems Improving Road Safety}

ITS is a collective name for a number of technology-based approaches that are designed to improve the quality, safety and efficiency of transport networks. Road safety and law enforcement is one of the most important application area of these systems (Khorasani et al., 2013). Intelligent Transport System solutions improve road safety by targeting specific risk factors, including vehicle, road environment and human factors that have been found to contribute to road accidents (Spyropoulou et al., 2007).

In-vehicle systems increase the safety of cars by reducing the probability of occurrence, or mitigating the effects of accidents (Van De Ven et al., 2013). Advanced driver assistance systems (ABS, ACC, ESP, ASR, BSW, etc.) are solutions like this. Although some of them currently operate autonomously, the collected data provide opportunities for communication systems and other vehicle systems, or units which are part of the infrastructure (Huang et al., 2013). The eCall project improves 
road safety by implementing automatic emergency calls in case of a crash and cutting emergency services response time (Cabo et al., 2014).

The safety of road infrastructure is also to be enhanced by ITS solutions. On the one hand, some systems were specially designed for this purpose; on the other hand some solutions with a different prime function also contribute to it. For example, traffic management systems can take safety concerns into account while seeking the local or network-wide traffic optimum. Camera systems, speed measuring and over speed warning signs stimulating drivers to comply with safety regulations by collecting data of the vehicles (Torok and Futyu, 2012). Variable message signs are able to give information about hazard situations, while other systems (e.g. collision avoidance and lane departure warning systems) help to forecast potential dangers and conflicts.

Intelligent systems are able to reduce the threatening effects of human factor too, by warning and supporting the drivers. With the use of fatigue monitoring systems, dangerous traffic situations can be prevented, while some other solutions (e.g. alcolock) prevent unsafe traffic participation (Akerstedt et al., 2003). The data collected by these devices are used by systems of other areas (police controls, databases, etc.) too. Smart devices of the road users make direct, personalized support and data collection possible.

To methodize Intelligent Transport Systems improving road safety, and to explore the development possibilities of existing systems, systematic analysis of relevant international researches have been carried out. European strategic documents (ETSC, 1999) have also been considered. In this paper, Intelligent Transport Systems have been classified according to the following aspects:

- most important strategical, professional and scientific classification orientations (presented in this section) have been considered,

- fundamental aims and main characteristics of the systems have been taken into account,

- a bottom-up approach has been applied.

This means - according to the reviewed literature - the groups mentioned in this chapter cover ITS systems framework considering the whole functional space. The identified ITS-groups and examples have been summarized in Table 1.

Table 1. The constructed ITS-groups and examples

\begin{tabular}{|l|l|l|}
\hline Notation & ITS-groups & Examples \\
\hline 1. & Intervention systems based on the condition of drivers & fatigue monitoring systems, alcolock \\
\hline 2. & Systems facilitate to comply with the rules of the roads & $\begin{array}{l}\text { overspeed warning systems, speed measuring and } \\
\text { displaying signs, intelligent cameras }\end{array}$ \\
\hline 3. & $\begin{array}{l}\text { Personalized, real-time, continuous traffic behaviour } \\
\text { monitoring and supporting systems }\end{array}$ & $\begin{array}{l}\text { fleet management systems, VEMOCO, smart phone } \\
\text { applications }\end{array}$ \\
\hline 4. & Dangerous traffic situation forewarning systems & variable message signs, meteorological systems \\
\hline 5. & Systems supporting rescue operations & eCall system \\
\hline 6. & $\begin{array}{l}\text { Integrated electronic driving license and registration } \\
\text { system }\end{array}$ & Smart Card systems (e.g. Gemalto, Netherlands) \\
\hline 7. & Traffic management systems & SITRAFFIC Scala, VEKTOR \\
\hline 8. & $\begin{array}{l}\text { Systems to create safety characteristics of road } \\
\text { infrastructure }\end{array}$ & $\begin{array}{l}\text { ROADMASTER-G, KARESZ, hazard maps, road } \\
\text { accident databases }\end{array}$ \\
\hline 9. & In-vehicle active safety systems & ACC, City Safety, ESP, ASR, BSW, FCW, LDW \\
\hline 10. & Compulsory, road safety supporting in-vehicle systems & Digital tachograph \\
\hline
\end{tabular}

Researches of the author focused on the evaluation of these ITS systems. Statistical analysis (KIPA-analysis) and a cluster analysis have been carried out to determine the target areas, where intelligent systems can have a significant effect in the future (Torok and Pauer, 2016).

To perform the examination, the methodology of the multi-criteria analyses was applied. Assessment criteria of the identified groups was generated by the involvement of 6 experts, from various areas (road safety, transport economy, system planning). The experts specified the following aspects with significance in road safety assessments:

1. Impact on road safety

2. Number of involved traffic participants

3. Implementation expenses

4. Protective effect (security)

5. Social/legal hindering factors.

The described ITS categories have been assessed according to the determined criteria by the experts. Average scores have been calculated with the following formula to provide basis for the fundamental table of the KIPA analysis and preparation of the cluster analysis: 
$P_{n, m}=\frac{\sum_{l} p_{l, n, m}}{\max (l)}, n=1 . .10 ; m=1 . .5 ; l=1 . .6 ;$ where

$n=$ index of ITS-groups,

$m=$ index of the aspects of the assessment,

$l=$ index of experts,

$p_{l, n, m}=$ score given to ITS-group $n$, according to aspect $m$ by expert $l$.

$P_{n, m}=$ experts average score given to ITS-group $n$, according to aspect $m$.

In order to study the appropriateness of analyses based on average expert opinion values, relative dispersion values of the average scores have been examined related to all ITS system groups according to the following formula:

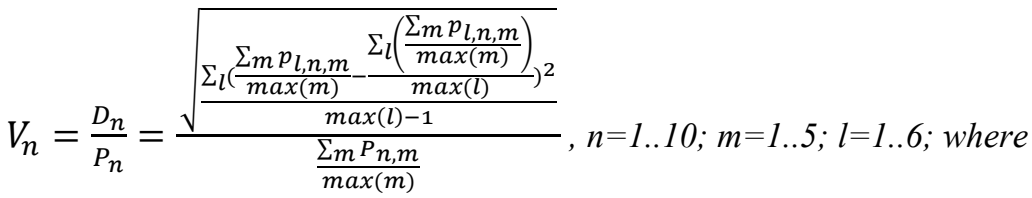

$V_{n}=$ relative dispersion value related to ITS-group $n$,

$D_{n}=$ dispersion value related to ITS-group $n$,

$P_{n}=$ average score of ITS-group $n$ (according to all experts on all aspects).

Average scores and relative dispersions have been summarized in Table 2.

Table 2. Average scores and relative dispersions of ITS-groups and aspects

\begin{tabular}{|c|c|c|c|c|c|c|}
\hline $\begin{array}{c}\text { ITS- } \\
\text { group }\end{array}$ & $\begin{array}{c}\text { Impact on road } \\
\text { safety } \\
\mathbf{( 0 , 2 4 6 )}\end{array}$ & $\begin{array}{c}\text { Number of } \\
\text { involved traffic } \\
\text { participants } \\
\mathbf{( 0 , 2 5 0 )}\end{array}$ & $\begin{array}{c}\text { Implementation } \\
\text { expenses } \\
\mathbf{( 0 , 3 0 4 )}\end{array}$ & $\begin{array}{c}\text { Protective effect } \\
\mathbf{( 0 , 0 7 5 )}\end{array}$ & $\begin{array}{c}\text { Social/legal } \\
\text { hindering factors } \\
\mathbf{( 0 , 1 2 5 )}\end{array}$ & $\begin{array}{c}\text { Rel. } \\
\text { disp. }\end{array}$ \\
\hline 1. & 5,33 & 4,83 & 5,83 & 2,50 & 5,67 & 0,25 \\
\hline 2. & 4,67 & 8,33 & 7,33 & 4,33 & 7,83 & 0,09 \\
\hline 3. & 4,67 & 7,00 & 3,83 & 7,33 & 4,67 & 0,25 \\
\hline 4. & 5,33 & 7,00 & 6,00 & 3,50 & 6,83 & 0,25 \\
\hline 5. & 4,50 & 5,00 & 7,33 & 3,83 & 8,00 & 0,18 \\
\hline 6. & 5,67 & 9,50 & 3,83 & 7,83 & 4,67 & 0,14 \\
\hline 7. & 3,83 & 6,33 & 4,83 & 2,33 & 6,00 & 0,24 \\
\hline 8. & 6,17 & 3,83 & 5,17 & 1,50 & 9,00 & 0,23 \\
\hline 9. & 7,00 & 8,00 & 8,00 & 5,50 & 8,50 & 0,25 \\
\hline 10. & 5,00 & 3,83 & 4,67 & 4,67 & 6,67 & 0,17 \\
\hline Rel. disp. & 0,21 & 0,18 & 0,08 & 0,21 & 0,38 & \\
\hline
\end{tabular}

In some cases, relative dispersions had values higher than the expected number of 0.2 , demonstrating the heterogeneous structure of the scoring system, however, no extreme values were observed, so the dispersions in our primary studies have been accepted and the sample have been considered well characterized by the average values.

Following the preparation, KIPA-analysis has been performed according to the following steps:

- aspects have been weighted by the experts (indicated in Table 2, first row);

- measurement scales of the assessment factors have been designed (by considering the weights);

- basic table of the KIPA-method have been formulated (by projecting qualitative scores of experts to the previous scale);

- KIPA matrix have been prepared (comparison in pairs);

- limit values of preference and disqualificance have been specified;

- preference order has been determined (Table 3) and assorting graph have been prepared (Fig 1).

The KIPA procedure is suitable for comparison of complex systems. Characterization of the alternatives takes place on scales formed based on the assessment criteria, based on the principle of even comparison (Kindler and Papp, 1977). The comparisons have been indicated in the KIPA matrix, which has been generated by the use of preference and disqualificance indices.

Preference index provides information on the advantage of the $i$ th alternative compared to the $j$ th one. Its value arises by summarizing those assessment criteria (in per cent) for which the particular ITS system group is preferred or neutral over against the compared alternative. By the determination of 
disadvantage indices, only that assessment aspect has been taken into account, for which the preference intensity is the highest. So in the first step the assessment aspect is selected where the absolute value of the difference between the values assigned to the $i$ th and $j$ th alternatives is the biggest (and value assigned to the $j$ th alternative is higher than the one assigned to the $i$ th element, according to the particular aspect). This value is then divided by the volume of the maximum scale (in our case this was the scale according to the road safety impact), then the result is multiplied by 100 to obtain the per cent form.

The preference threshold value was taken at a $60 \%$ level (cij $\geq 60 \%$ ) and the disqualificance threshold value at $30 \%$ level $(\mathrm{dij} \leq 30 \%)$ into account; these limits were satisfied by 34 pair wise comparisons.

Based on the results, ranking of the identified ITS-groups have been specified (Table 3).

Table 3. Order of preference (results of KIPA analysis)

\begin{tabular}{|c|l|c|c|}
\hline $\begin{array}{c}\text { Preference } \\
\text { order }\end{array}$ & \multicolumn{1}{|c|}{ ITS-group } & $\begin{array}{c}\text { Preferred to } \\
\text { alternatives } \\
\text { [pcs] }\end{array}$ & $\begin{array}{c}\text { Dominated by } \\
\text { alternatives } \\
\text { [pcs] }\end{array}$ \\
\hline 1. & 9. In-vehicle active safety systems & 9 & 0 \\
\hline 2. & 2. Systems facilitate to comply with the rules of the roads & 7 & 1 \\
\hline 3. & 4. Dangerous traffic situation forewarning systems & 5 & 2 \\
\hline 4. & 5. Systems supporting rescue operations & 4 & 2 \\
\hline 5. & 1. Intervention systems based on the condition of drivers & 4 & 4 \\
\hline 6. & 8. Systems to create safety characteristics of road infrastructure & 3 & 5 \\
\hline 7. & 6. Integrated electronic driving license and registration system & 1 & 1 \\
\hline 8. & 10. Compulsory, road safety supporting in-vehicle systems & 1 & 6 \\
\hline 9. & 7. Traffic management systems & 0 & 6 \\
\hline 10. & $\begin{array}{l}\text { 3. Personalized, real-time, continuous traffic behaviour monitoring and } \\
\text { supporting systems }\end{array}$ & 0 & 7 \\
\hline
\end{tabular}

Preferences of the ITS-systems have been illustrated by an assorting graph (Fig. 1). Nodes of the graph have been formed by the ITS-groups. Directed edges between the compared pairs of elements start from the preferred alternative.

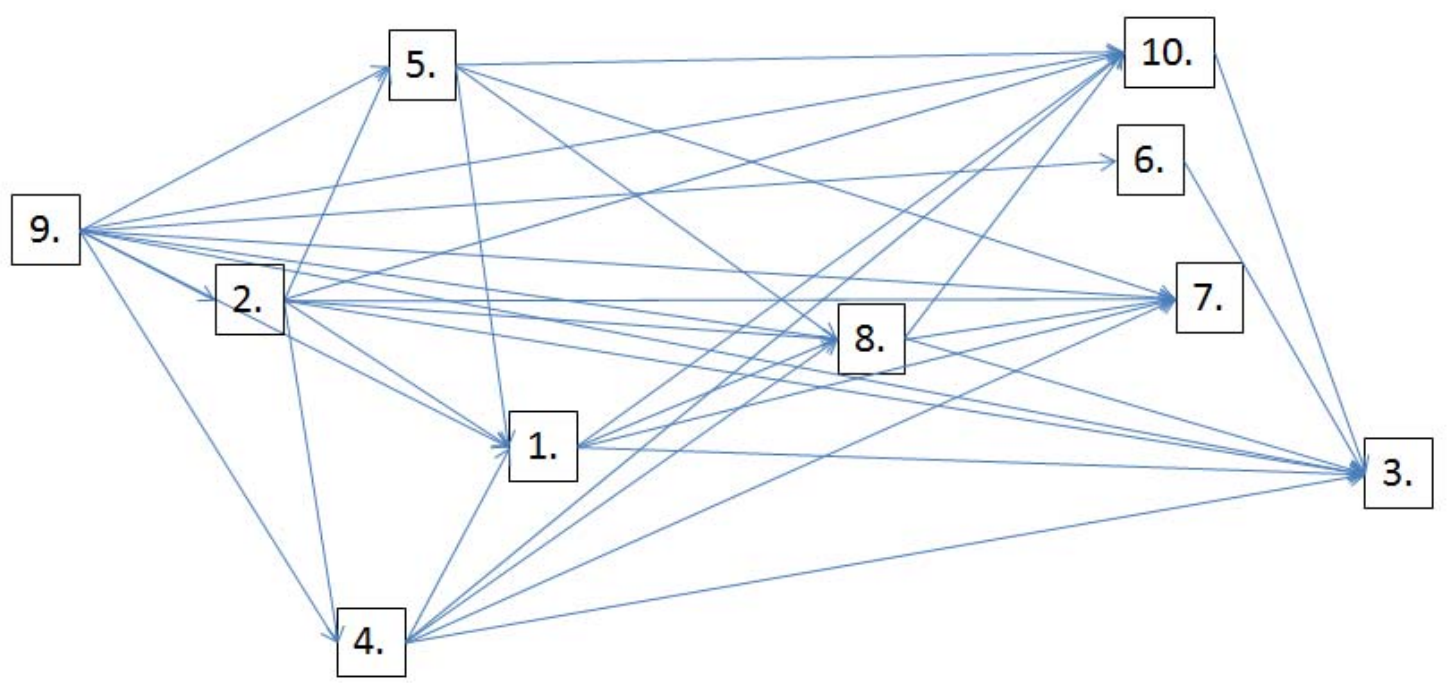

Figure 1. Assorting graph of the ITS-groups (Torok and Pauer, 2016)

Cluster analysis has been performed in the IBM SPSS Statistics program. The ITS-groups have been classified into different sized clusters, of which the most homogeneous number of elements has been experienced in case of 3 clusters.

The cluster analysis resulted similar outcomes to KIPA analysis. Cluster 1 with "extremely good" results from the most aspects has been formed by ITS-groups marked by number 2., 4., 5. and 9.: they increase road safety in a very effective way, while the stratum of involved traffic participants is very wide, too. Social/legal difficulties of their introduction are lower than the average and their implementation expenses are advantageous. A slightly lower than average value has only been observed related to their protective functions (Torok, 2016b). Cluster 2 has been formed by ITS-groups 3. and 6 ., with lower road safety effects and higher costs, but outstanding security effects. ITS-groups 1., 7., 8. and 
10. have been classified in Cluster 3: these systems are characterized by lower than the average road safety effects, security functions and number of involved travellers.

Thus, our statistical analyses (based on experts opinions) resulted, that an extensive introduction, application and support of the in-vehicle active road safety systems; systems facilitated to comply with the Highway Code rules; forewarning systems; as well as systems supporting the rescue operations are highly recommended.

\section{Evolving and Methodizing the Strategy of Intelligent Transport Systems Improving Road Safety}

To investigate the applicability and future development opportunities of ITS systems related to road safety, it is necessary to take many complex aspects into account. Road safety aspects have been brought into relief and security aspects have also been considered, as development goals and trends in the European Union stresses the importance of examination of safety systems' role in security.

Main characteristics of input and output data (place, time, purpose of data collection, etc.) and connection areas of systems have been investigated. Risks of data management have been estimated by experts, as a main challenge related to innovative ITS solutions is ensuring privacy (Foss, 2014). In addition, governmental tasks in strategic implementation have been determined and expected benefit-cost ratios (BCR) of dissemination of ITS solutions have been estimated.

Cost-benefit analysis (CBA) is a method of a systematic process for calculating and comparing benefits and costs of a project, decision or government policy. It has two main purposes:

- to determine if it is a sound investment/decision (justification/feasibility),

- to provide a basis for comparing projects. It involves comparing the total expected cost of each option against the total expected benefits, to see whether the benefits outweigh the costs, and by how much.

From road safety point of view, avoiding the accidents, injuries, and fatalities is the most important issue (Elvik et al., 2009). Besides avoiding them, lives can be saved; also we may avoid the external costs, caused by the accidents. Defining the loss value of the accident costs is difficult, although the values of injuries with fatal, serious and light results have been estimated, it is hard to define the effect of the ITS related interventions on the accident rates. On the other hand, external economic effects of interventions like this are hard to be estimated. The methodology of the BCR used to indicate the rate of return of the implementation of ITS systems has been based on previous project experiences, namely RoseBud (Winkelbauer and Stefan, 2005), (Vlakveld et al., 2005) and SafetyNet (SafetyNet, 2009) projects. The cost benefit analysis of the mentioned projects has determined intervals of the return rate of each action implemented in Rosee project (KTI, 2015). These intervals were the following:

- $\mathrm{BCR}<1$ : costs outweigh the benefits,

- $1 \leq \mathrm{BCR}<2$ : average benefits,

- $2 \leq \mathrm{BCR}<5$ : benefits are above average,

- $5 \leq \mathrm{BCR}$ : high benefits.

The interval of the return ratio of each ITS-group has been determined based on the previous projects' results, so they strongly depend on experts' estimations.

Along with ITS-groups, intelligent system's potential development opportunities, strategic objectives of their safety and security functions have been summarized in the following points.

\subsection{Intervention systems based on the condition of drivers}

Medium-term development possibility of intervention systems based on the condition of drivers is the spread of in-vehicle, autonomous control systems. The long-term strategy should be the implementation of an online-system, which provides the possibility to log driving activities under influenced (by alcohol or drugs) or tired conditions in a central database. Main functions of the systems of this ITS-group are: preventing driving activities under unsafe conditions of the drivers, monitoring and "aftercareing" the recidivist drivers. Secondary functions are the analysis of the drivers' attitude and profile attributes with the use of data mining methods.

\subsection{Systems facilitate to comply with the rules of the roads}

Medium-term development trend of this group is wider spread of online surveillance systems (fixed and mobile units outside of the vehicles) as well as implementation of network operation of them. 
Long-term strategic objective is the application of in-vehicle systems, which are able to prevent violations on the roads. Surveillance systems significantly increase the probability of being caught, as camera systems are capable of identifying and monitoring road users with potential security risks. In-vehicle systems provide options for prevention of risky, offending behaviour as well. Secondary functions are the analysis of the drivers' attitude and profile attributes with the use of data mining methods. Recorded locomotion processes make it possible to estimate from-to matrixes. The data provide options also for analyzing main causes of spatial densification of road accidents, and for revising the weights of accident factors.

\subsection{Personalized, real-time, continuous traffic behaviour monitoring and supporting systems}

The medium-term vision is the spread of applications for commonly used smart devices that are able to monitor the locomotion habits of road users (e.g. mode selection, speed, road safety aspects) and use that to draw up suggestions for mobility behaviour. Based on that, online social networks should be formed to contribute to the emergence of shareable, individual transport profiles. Therefore, primary aim (development of individual transport attitude) of the ITS-group is to be achieved by community systems. Secondary functions are the analysis of the drivers' attitude and profile attributes with the use of data mining methods. Recorded locomotion processes make it possible to estimate from-to matrixes. The data provide options also for analyzing the causes of spatial densification of road accidents, and for revising the weights of accident factors. Besides that, under certain circumstances the systems are capable of keeping track of road users with potential security risks.

\subsection{Dangerous traffic situation forewarning systems}

Strategic goal is the spread of supporting applications for commonly used smart devices that are able to continuously monitor the current position and motion characteristics of the road users. These systems are able to forewarn drivers about potential dangers. In future, such online social networks and applications should be spread that are able to forecast potential conflicts and provide real-time road safety information. Primary function of these ITS systems is to forewarn drivers about dangerous situations based on static road parameters (accident data, curve radius, gradient, etc.), and dynamic data (position, motion characteristics, etc.) sourced from road users. Based on the number of forecasted conflicts, search of particularly dangerous road sections and analysis of the driver's attitude and profile attributes becomes possible. Under certain circumstances the systems are also capable of keeping track of road users with potential security risks.

\subsection{Systems supporting rescue operations}

Systems supporting rescue operations significantly reduce the outcomes of accidents that have already occurred. The spread of in-vehicle, automatic emergency systems are the key factor of development, as the technology is already market-ready. Actual position data, motion characteristics and static GIS road data make it possible to start automatic or semi-automatic emergency calls. The primary purpose of supporting systems is to transmit the position and basic features of road accidents to the nearest emergency call centre immediately after the accident. This improves the efficiency and decreases the time of rescue operation, thereby the system is able to reduce the number of road accident deaths, and also contribute to reducing the rate of injuries. The recorded features of accidents can be analyzed with data mining methods; search of particularly dangerous road sections becomes possible. Besides that, the systems are capable of identifying and monitoring road users with potential security risks.

Safety and security systems of vehicles used in public transport are also included in the ITS-group. Intelligent systems of these vehicles (complex cameras, recorder and alarm modules) have monitoring and controlling functions as well.

\subsection{Integrated electronic driving license and registration system}

Introduction of an integrated e-driving license is a medium term vision. Long term strategic goal is the implementation of a complete database of the road users and an automatic control system (fixed and mobile units, smart devices) with several benefits: improved police roadside checks, increased probability of being caught and improved possibilities of sanctioning foreign drivers. In the long term it could also contribute to automation and unification of real-time authentication and identification processes, and to 
the implementation of automatic roadside checks. These operations can be extended to other general processes and operations that are not only associated with transport. The ITS-solution is especially capable of identifying and monitoring road users with potential security risks and is suitable for automatic implementation of specific control operations.

\subsection{Traffic management systems}

Optimization processes of traffic management and control systems are based on demand-driven, dynamic, locally used multivariate objective functions (taking road safety aspects into consideration). The spread of similar, but systemic traffic management and control systems implementing system-wide optimum is necessary. The main purpose of these systems is the implementation of local/system-wide condition-based traffic management, which takes the impacts of traffic characteristics on road safety into account. Recording of traffic data makes it possible to estimate from-to matrixes. Under certain circumstances the systems are capable of keeping track of road users with potential security risks.

\subsection{Systems to create safety characteristics of road infrastructure}

Implementation of systems that make periodically measurement and analysation of the transport system possible based only on basic (infrastructure, accident data etc.) and GIS data, ensures the creation of road safety characteristics. Strategic goal is the implementation of systems that are applicable for this purpose. In case of elementary realization (mid-term), primary functions are the (GIS based) safety classification of road network and the performance of tasks related to infrastructure management processes. In the future, road safety rating of transport network and its visualization in routing algorithms becomes possible with GIS based, real-time, continuously published display. Investigation of the correlation between the accident data and the characteristics of the infrastructure can be mentioned as a secondary function, just like the creation of an accident estimation model, and the identification of particularly dangerous road sections with the use of spatial autocorrelation models.

\subsection{In-vehicle active safety systems}

In-vehicle, advanced driving assistance systems are improving road safety, however, most of them currently operate autonomously. Mid-term strategic goal is wider spread of these systems and implementation of them in communication processes. In the future, implementation of systems controlling complete processes related to the motion of vehicles (parking, lane tracking etc.) and networkbased operation of them is the main objective. These systems are able to prevent car accidents, or mitigate the outcomes of them by recognizing and preventing unsafe situations and performing dynamic driving operations. Systems of this ITS-group make blocking and controlling vehicles with security risks possible.

\subsection{Compulsory, road safety supporting in-vehicle systems}

In medium term, unification of compulsory, in-vehicle systems supporting road safety is expected. Tachographs are able to inspect official drivers, and ensure feedback for operators, the use of them is regulated by law. This kind of inspection is to be extended for beginner drivers too. Strategic goal is the implementation of an online system, which is able to centrally log the driving activities and perform automatic checks based on them. Primary functions of the systems are the continuous monitoring of driving activities of relevant group of drivers (official, beginner etc.), the feedback of typical problems, mistakes and the real-time electronic check and automatic sanction of committed offenses. Besides that, the system is capable of recording data in case of accidents, and keeping track of road users with potential security risks.

Development possibilities, strategic objectives and characteristics of the defined ITS-groups have been summarized in Table 4, and Table 5. In Table 4, required input data and their specifications (location/time of collection) have been identified. Owners of the data have also been indicated. In Table 5, scope of the output data provided by the advanced ITS systems as well as target group of these data have been identified. Besides that, tasks and parameters related to the implementation of the systems (governmental tasks, privacy criteria and risks, estimated BCR etc.) have been summarized. 
Table 4. Specifications of required input data

\begin{tabular}{|c|c|c|c|c|}
\hline \multirow{2}{*}{ ITS-group } & \multicolumn{4}{|c|}{ Input data } \\
\hline & scope & location of collection & time of collection & owner $^{1}$ \\
\hline 1. & condition of drivers & vehicles & $\begin{array}{c}\text { during vehicle start-up and } \\
\text { driving }\end{array}$ & a \\
\hline 2. & $\begin{array}{l}\text { motion characteristics of vehicles } \\
\text { (speed values, static and dynamic } \\
\text { parameters of traffic control) }\end{array}$ & $\begin{array}{l}\text { mid-term: infrastructure } \\
\text { long-term: vehicles }\end{array}$ & $\begin{array}{l}\text { during the vehicle is } \\
\text { moving }\end{array}$ & a \\
\hline 3. & $\begin{array}{c}\text { individual motion characteristics, } \\
\text { parameters describing transport } \\
\text { system }\end{array}$ & $\begin{array}{l}\text { continuously used smart } \\
\text { devices of road users }\end{array}$ & during locomotion & $\mathrm{b}$ \\
\hline 4. & $\begin{array}{c}\text { individual motion characteristics, } \\
\text { parameters describing transport } \\
\text { system }\end{array}$ & $\begin{array}{l}\text { continuously used smart } \\
\text { devices of road users }\end{array}$ & during locomotion & $\mathrm{b}$ \\
\hline 5. & $\begin{array}{l}\text { motion characteristics of vehicles, } \\
\text { data of sensors }\end{array}$ & $\begin{array}{c}\text { mid-term: vehicles, } \\
\text { infrastructure } \\
\text { long-term: smart devices also }\end{array}$ & during locomotion & a \\
\hline 6. & $\begin{array}{l}\text { driver's license number, license } \\
\text { plate number, IDs }\end{array}$ & $\begin{array}{l}\text { the vehicles at fix checkpoints } \\
\text { and smart devices }\end{array}$ & continuous & a \\
\hline 7. & traffic parameters & $\begin{array}{c}\text { mid-term: infrastructure } \\
\text { long-term: vehicles and smart } \\
\text { devices also }\end{array}$ & continuous & $\mathrm{b}, \mathrm{c}$ \\
\hline 8. & infrastructure parameters & $\begin{array}{l}\text { vehicles during visitations, } \\
\text { studies of experts }\end{array}$ & periodic/ continuous & $\mathrm{b}$ \\
\hline 9. & $\begin{array}{l}\text { motion characteristics of vehicles, } \\
\text { data of sensors }\end{array}$ & $\begin{array}{c}\text { mid-term: vehicles, } \\
\text { infrastructure } \\
\text { long-term: smart devices also }\end{array}$ & during locomotion & d \\
\hline 10. & $\begin{array}{l}\text { motion characteristics of vehicles, } \\
\text { data of drivers, rules and laws }\end{array}$ & $\begin{array}{l}\text { mid-term: vehicles } \\
\text { long-term: infrastructure }\end{array}$ & during locomotion & $a, b$ \\
\hline
\end{tabular}

${ }^{1}$ Input data owner: a: interior ministry; b: background institutions of transport ministry; c: background institutions of local governments; $\mathbf{d}$ : vehicle systems

Table 5. Specifications of output data and parameters related to implementation

\begin{tabular}{|c|c|c|c|c|c|c|c|}
\hline \multirow[b]{2}{*}{ ITS-group } & \multicolumn{2}{|l|}{ Output data } & \multirow{2}{*}{$\begin{array}{c}\text { Govern- } \\
\text { mental } \\
\text { tasks }^{3} \\
\end{array}$} & \multirow{2}{*}{$\begin{array}{l}\text { Connect- } \\
\text { ion } \\
\text { areas }^{4} \\
\end{array}$} & \multirow{2}{*}{$\begin{array}{l}\text { Privacy } \\
\text { criteria }^{5}\end{array}$} & \multirow{2}{*}{$\begin{array}{c}\text { Privacy } \\
\text { risks }^{6}\end{array}$} & \multirow{2}{*}{$\begin{array}{l}\text { Esti- } \\
\text { mated } \\
\text { BCR }^{7}\end{array}$} \\
\hline & scope & $\begin{array}{l}\text { target } \\
\text { group }\end{array}$ & & & & & \\
\hline 1. & $\begin{array}{l}\text { 1. identification of risky drivers } \\
\text { (from the aspect of driving under } \\
\text { influenced condition) } \\
\text { 2. generate related statistics }\end{array}$ & $\mathrm{b}, \mathrm{c}$ & $\mathrm{b}, \mathrm{c}$ & $\mathrm{a}, \mathrm{b}$ & 1 & 2 & 1 \\
\hline 2. & $\begin{array}{l}\text { 1. identification of violators } \\
\text { 2. generate related statistics }\end{array}$ & $\mathrm{b}, \mathrm{c}$ & $\mathrm{a}, \mathrm{b}, \mathrm{c}, \mathrm{d}$ & $\mathrm{a}, \mathrm{b}, \mathrm{c}$ & 1 & 2 & 1 \\
\hline 3. & $\begin{array}{l}\text { 1. suggestions related to travel } \\
\text { behaviour } \\
\text { 2. generate related statistics }\end{array}$ & $\mathrm{b}, \mathrm{c}, \mathrm{e}$ & $\mathrm{a}, \mathrm{c}, \mathrm{d}$ & $\mathrm{a}$ & 1 & 2 & 3 \\
\hline 4. & $\begin{array}{l}\text { 1. real-time forewarning of potential } \\
\text { conflicts } \\
\text { 2. route recommendation } \\
\text { 3. generate related statistics }\end{array}$ & b. c, e & $\mathrm{a}, \mathrm{c}, \mathrm{d}$ & $\mathrm{a}$ & 1 & 2 & 3 \\
\hline 5. & $\begin{array}{l}\text { 1. GPS data } \\
\text { 2. on-site camera: identification } \\
\text { 3. weather and traffic information }\end{array}$ & $\begin{array}{c}\mathrm{a}, \mathrm{b}, \mathrm{c}, \\
\mathrm{e}\end{array}$ & $\mathrm{a}, \mathrm{c}, \mathrm{e}$ & $\mathrm{a}, \mathrm{b}, \mathrm{c}$ & 1 & 2 & 1 \\
\hline 6. & $\begin{array}{l}\text { 1. identification } \\
\text { 2. filtration } \\
\text { 3. approval }\end{array}$ & $\begin{array}{c}\mathrm{a}, \mathrm{b}, \mathrm{c}, \\
\mathrm{e}\end{array}$ & $\mathrm{a}, \mathrm{b}, \mathrm{c}, \mathrm{e}$ & $a, b, c$ & 1 & 1 & 1 \\
\hline 7. & traffic controlling signals & $\mathrm{d}$ & $\mathrm{a}$ & $\mathrm{a}, \mathrm{b}, \mathrm{c}$ & 2 & 3 & 1 \\
\hline 8. & $\begin{array}{c}\text { safety characteristics of road } \\
\text { infrastructure }\end{array}$ & $\mathrm{b}, \mathrm{d}$ & $\mathrm{a}, \mathrm{e}$ & $\mathrm{a}$ & 3 & 3 & 3 \\
\hline 9. & $\begin{array}{l}\text { 1. identification of emergencies and } \\
\text { potential conflicts } \\
\text { 2. intervention }\end{array}$ & $\mathrm{d}$ & $\mathrm{a}, \mathrm{b}, \mathrm{c}, \mathrm{d}$ & $\mathrm{b}$ & 2 & 3 & 2 \\
\hline 10. & $\begin{array}{l}\text { 1. suggestions for mobility behaviour } \\
\text { 2. identification of risky traffic } \\
\text { behaviours } \\
\text { 3. identification of violations and } \\
\text { emergencies }\end{array}$ & $\mathrm{a}, \mathrm{b}$ & $\mathrm{a}, \mathrm{b}, \mathrm{c}, \mathrm{d}$ & $b, d$ & 1 & 2 & 2 \\
\hline
\end{tabular}

${ }^{2}$ Output data target group: a: same; b: same; c: establishments responsible for preventing accidents; d: road users; e: other public and market establishments 
${ }^{3}$ Governmental tasks: a: investment- system development; b: preparation of legislation; c: raise awareness, disseminate knowledge, d: partly operation; e: operation

${ }^{4}$ Connection areas: a: total transportation sector; b: road transport: vehicle; c: road transport: infrastructure; d: driver (individual)

${ }^{5,6}$ Privacy criteria and risks: 1: high level safety criteria and risks; 2: average safety criteria and risks; 3: safety criteria and risks below average

${ }^{7}$ Estimated $B C R$ : 1: average $(1 \leq \mathrm{BCR}<2) ; 2$ : above average $(2 \leq \mathrm{BCR}<5)$; 3: high $(5 \leq \mathrm{BCR})$

\section{Conclusions}

In this article, Intelligent Transport Systems improving road safety have been classified and evaluated. Order of preference between ITS-groups has been determined with the use of KIPA-method and cluster analysis. Results of different methods pointed to the same direction proving that certain measurements are especially efficient taking all specified criteria (economic, safety, security aspects) into account. The results greatly contributed to the determination of development directions of the Hungarian National Strategy on Intelligent Transport Systems.

Beside efficiency in road safety, investigation of temporality of these ITS-groups is also an important input of strategy development. Hence, strategic objectives of the systems have been determined in a systemoriented approach. Medium and long-term development opportunities, primary and secondary functions of ITS solutions have been investigated. Other typical parameters related to strategic objectives (location and time of data collection, estimated BCR of investments etc.) have been summarized in tabular form. The need of connecting the systems with networking, and achieving the correct depth of functionality was a main aspect when establishing these objectives. One of the primary tasks of the strategy is to create potential of innovative solutions that follow from rapidly developing information technologies. Taking European Union standards into account and unifying the system's communication channels and data exchange methods are crucial, as intelligent transport systems becomes more and more advanced and extensive. In order to ensure dynamic expansion, it is necessary to put a high priority on unification and clarification of the conditionality of open access to information. When implementing the systems, completion of project planning phases and cost-benefit analysis related to ITS solutions are also needed.

Taking into account road safety aspects contributes to a comprehensive and effective ITS strategy that is in accordance with the formulated objectives. The analysis method implemented in this article makes strategy development more extensive and effective by methodizing complex parameters beside road safety effects. With different weighting of the aspects identified (safety and security effects, temporality, cost-effectiveness, governmental tasks etc.), complex, parameterized packages of measures can be set up with different purposes and horizon.

\section{References}

1. Akerstedt, T., Mollard, R., Samel, A., Simons, M., Spencer, M., Mcdonald, N. (2003) European Transport Safety. In: ETSC Meeting to discuss the role of EU FTL legislation in reducing cumulative fatigue in civil aviation, Brussels, February 2003. https://www.eurocockpit.be/sites/default/files/Akerstedt-Mollard-Samel-Simons-Spencer-2003.pdf

2. Cabo, M., Fernandes, F., Pereire, T., Fonseca, B., Paredes, H. (2014) Universal Access to eCall System. Procedia Computer Science, Volume 27, 104-112. DOI:10.1016/j.procs.2014.02.013.

3. Elvik, R. (2000) How much do road accidents cost the national economy? Accident Analysis \& Prevention, 32(6), 849-851. DOI:10.1016/S0001-4575(00)00015-4.

4. Elvik, R., Hoye, A., Vaa, T., Sorensen, M. (2009) Road Design and Road Equipment. The handbook of road safety measures, pp. 144-333. ISBN: 978-1-84855-250-0. DOI: 10.1108/9781848552517-007

5. European Transport Safety Council (ETSC). (1999) INTELLIGENT TRANSPORTATION SYSTEMS AND ROAD SAFETY. ETSC, Brussels 1999. ISBN: 90-76024-05-7

6. Foss, T. (2014) Safe and Secure Intelligent Transport Systems (ITS). Proceedings of Transport Research Area (TRA) 5th Conference on Transport at Solutions from Research to Deployment. Paris, France, April 2014.

7. Garcia-Altés, A. and Pérez, K. (2007) The economic cost of road traffic crashes in an urban setting. Injury Prevention, 13(1), 65-68.DOI:10.1136/ip.2006.012732.

8. Huang, L., Yao, J., Wu, W., Yang, X. (2013) Feasibility Analysis of Vehicle-to-vehicle Communication on Suburban Road. PROMET - Traffic \& Transportation Research, 25(5). DOI: http://dx.doi.org/10.7307/ptt.v25i5.446 
9. Hughes, B.P., Newstead, S., Anund, A., Shu, C.C., Felkmer, T. (2015) A review of models relevant to road safety. Accident Analysis \& Prevention, Volume 74, 250-270. DOI:10.1016/j.aap.2014.06.003.

10. Jarasuniene, A. and Jakubauskas, G. (2007) Improvement of Road Safety Using Passive and Active $\begin{array}{lllll}\text { Intelligent } \quad \text { Vehicle } & \text { Safety } & \text { Systems. } & \text { Transport, } & \text { 22(4), }\end{array}$ DOI:10.1080/16484142.2007.9638143

11. Khorasani, G., Tatari, A., Yadollahi, A., Rahimi, M. (2013) Evaluation of Intelligent Transport System in Road Safety. International Journal of Chemical, Environmental \& Biological Sciences (IJCEBS), 1(1), 110-118.

12. Kindler, J., Papp, O. (1977) Komplex rendszerek vizsgálata- Összemérési módszerek. (Study of Complex Systems-Matching Methods). Müszaki Könyvkiadó (Technical Publishing House). Budapest, 41, 151-175. ISBN: 963101830 XKTI Institute for Transport Sciences Nonprofit Ltd. (2014) Analysis of cost effectiveness of pilot actions. ROSEE (Road Safety in South East European Regions) Report. Budapest, Hungary, November 2014.

13. KTI Institute for Transport Sciences Nonprofit Ltd. (2015) National Strategy of ITS, Hungary. Budapest (document under construction).

14. Oei, H.L. and Polak, P.H. (2002) Intelligent Speed Adaptation (ISA) and Road Safety. IATSS Research, 26(2), 45-51. DOI:10.1016/S0386-1112(14)60042-X.

15. Rosolino, V., Iuele, T., Astarita, V., Festa D., C., Tassitani, A., Rogano, D., Zaffino, C. (2014) Road Safety Performance Assessment: A New Road Network Risk Index for Info Mobility. Procedia Social and Behavioural Sciences, Volume 111, 624-633. DOI:10.1016/j.sbspro.2014.01.096.

16. SafetyNet. (2009) Cost-benefit analysis. Web-text. Retrieved: 2016.03.02. URL: https://ec.europa.eu/transport/road_safety/sites/roadsafety/files/specialist/knowledge/pdf/cost_benefit analysis.pdf

17. Spyropoulou, I., Golias, J., Karlaftis, M., Penttinen, M., Vaa, T. (2007) Risk factors and Intelligent Transport System answers- possible opportunities and shortcomings. Proceedings of the 11th World Conference on Transportation Research. Berkeley, USA, June 2007.

18. Torok, A. (2015) Analysing the Connection of Hungarian Economy and Traffic Safety. Periodica Polytechnica Transportation Engineering, 43(2), 106-110. DOI:10.3311/PPtr.7953.

19. Torok, A. (2016a) A közlekedésbiztonságot javító intelligens közlekedési rendszerek és szolgáltatások fejlődési lehetőségeinek, stratégiai célkitűzéseinek meghatározása (In Hungarian). Útügyi Lapok, Issue 7.

20. Torok, A. (2016b) Statistical Analysis of a Multi-Criteria Assessment of Intelligent Traffic Systems for the Improvement of Road Safety. Journal of Finance and Economics, 4(5), 127-135. http://pubs.sciepub.com/jfe/4/5/1

21. Torok, A., Futyu, I. (2012) Investigating the effects of transport safety- and infrastructuredevelopment with the use of SCGE models in the material flows. In: 2012 IEEE 10th Jubilee International Symposium on Intelligent Systems and Informatics, SISY, Subotica, September 2012. pp. 199-203. DOI:10.1109/SISY.2012.6339514.

22. Torok, A., Pauer, G. (2016) Intelligens közlekedési rendszerek közlekedésbiztonsági rangsorolása (In Hungarian). Statisztikai Szemle, 94(4), 418-434.

23. Van De Ven, T., Long, J., Wedlock, M. (2013) ITS ACTION PLAN. Free Road Safety Traffic Information. 22. Jan. 2013. Retrieved from http://ec.europa.eu/transport/themes/its/studies/its_en.htm.

24. Vlakveld, W.P., Wesemann, P., Devillers, E.L.C., Elvik, R., Veisten, K. (2005) Detailed cost-benefit analysis of potential impairment countermeasures. $R$-2005-10. SWOV, Leidschendam, Netherlands.

25. Winkelbauer, M., Stefan, C. (2005) Testing the efficiency assessment tools on selected road safety measures. Final report Workpackage 4 of the European research project ROSEBUD. European Commission, Brussels.

26. Yang, S., Lu, S., Wu, Y-J. (2013) GIS-based Economic Cost Estimation of Traffic Accidents in St. Louis, Missouri. Procedia Social and Behavioural Sciences, Volume 96, 2907-2915. DOI:10.1016/j.sbspro.2013.08.322. 